\title{
Change in osmolarity of disodium cromoglycate solution and protection against exercise-induced bronchospasm in children with asthma
}

\author{
S. Kano*\#, T. Hirose*, S. Nishima*
}

Change in osmolarity of disodium cromoglycate solution and protection against exercise-induced bronchospasm in children with asthma. S. Kano, T. Hirose, S. Nishima. C) ERS Journals Ltd 1996.

ABSTRACT: It has been suggested that osmolarity and/or nebulizer output may affect the protective effects of disodium cromoglycate (DSCG) in asthma. The aim of this study was to evaluate the influence of osmolarity of the DSCG solution on exercise-induced bronchospasm (EIB) in children with bronchial asthma. A jet nebulizer was used for DSCG inhalation in Study 1 and an ultrasonic nebulizer in Study 2. Thirteen asthmatic children ( 7 males and 6 females, aged 6-14 yrs) were enrolled in Study 1, and nine asthmatic children (5 males and 4 females, aged 9-13 yrs) in Study 2. After pretreatment with saline (control), hypotonic DSCG or isotonic DSCG, children underwent exercise challenge with a cycle ergometer. The percentage fall in forced expiratory volume in one second (FEV1) was measured at 5 and 15 min postexercise. The data were compared by analysis of variance (ANOVA).

Both in Study 1 and Study 2, there were no significant differences in minute ventilation volume or maximum heart rate during exercise between the different treatment groups. Both hypotonic and isotonic DSCG significantly reduced the maximum percentage fall in FEV1. There were no significant differences in protective effects between hypotonic and isotonic DSCG in either study.

We conclude that the efficacy of hypotonic and isotonic disodium cromoglycate solutions is similar for protection against exercise-induced bronchospasm. Hypotonic disodium cromoglycate seems to be clinically effective for prevention of exerciseinduced bronchospasm and treatment of asthmatic children.

Eur Respir J., 1996, 9, 1891-1895.

Disodium cromoglycate (DSCG) has been used for treatment of asthma, and for preventing attacks of exercise-induced bronchospasm (EIB) [1-3]. It is administered as a powder or in aerosol form by use of different devices for inhalation [4-7]. WEINER et al. [8] reported that isotonic nebulized DSCG provided better protection against EIB than hypotonic DSCG (1\% in distilled water, about $40 \mathrm{MOsm} \cdot \mathrm{L}^{-1}$ ), which is standard and commercially available. These investigators did not specify the kind of nebulizer used for inhalation in their study. The influence of osmolarity on airways may differ for the various nebulizers. Ultrasonic nebulizers appear to have a greater influence on the osmolarity load in the airways as compared with jet nebulizers, because an ultrasonic nebulizer is capable of producing dense aerosols and has a greater output. Ultrasonic nebulizers are frequently used for osmolarity challenge tests, such as with distilled water, and hypertonic saline $[9,10]$. Evaporative cooling, which can affect the osmolarity of droplets, has been demonstrated when a jet nebulizer was used [11].

Our objective was to evaluate the influence of a change in osmolarity of the DSCG solution on EIB in children with bronchial asthma. Both jet and ultrasonic nebulizers, which are frequently used for management of asthma in children, were used in this study.

\section{Study subjects}

\section{Study design}

*Dept of Pediatrics and \#Clinical Research Institute, National Minami-Fukuoka Chest Hospital, Fukuoka, Japan.

Correspondence: S. Kano

Dept of Pediatrics

National Minami-Fukuoka Chest Hospital 4-39-1 Yakatabaru

Minami-ku

Fukuoka City

Japan 815

Keywords: Asthma

disodium cromoglycate

exercise-induced bronchospasm

osmolarity

Received: April 101995

Accepted after revision May 271996

Thirteen asthmatic children ( 7 males and 6 females; aged 6-14 yrs) were enrolled in Study 1, and nine asthmatic children (5 males and 4 females; aged 9-13 yrs) were enrolled in Study 2. All subjects satisfied the criteria of bronchial asthma recommended by the American Thoracic Society (ATS) and were clinically stable. No subjects had received oral or intravenous corticosteroids in the last 2 months. All medications were withheld for at least $18 \mathrm{~h}$ before exercise challenge. Individual daily medications are shown in tables 1 and 2, and the regimen was maintained throughout the study. Informed consent was provided by the subjects' parents.

A jet nebulizer was used in Study 1 and an ultrasonic nebulizer in Study 2 for inhalation of DSCG before exercise challenge. In each study, inhalations of normal saline, isotonic DSCG or hypotonic DSCG were given 
Table 1. - Individual pulmonary function and percentage fall in FEV1 after exercise with inhalation by jet nebulizer (Study 1)

\begin{tabular}{|c|c|c|c|c|c|c|c|c|c|c|c|c|c|c|c|c|}
\hline \multirow[b]{3}{*}{$\begin{array}{l}\text { Subject } \\
\text { No. }\end{array}$} & \multirow[b]{3}{*}{ Sex } & \multirow[b]{3}{*}{$\begin{array}{l}\text { Age } \\
\text { Yrs }\end{array}$} & \multirow{3}{*}{$\begin{array}{l}\text { Pred } \\
\text { FEV1 } \\
\text { L }\end{array}$} & \multicolumn{4}{|c|}{ Control (normal saline) } & \multicolumn{4}{|c|}{ Hypotonic DSCG } & \multicolumn{4}{|c|}{ Isotonic DSCG } & \multirow[b]{3}{*}{$\begin{array}{c}\text { Daily } \\
\text { medication }\end{array}$} \\
\hline & & & & \multirow[b]{2}{*}{ (A) } & \multicolumn{3}{|c|}{ FEV1 } & \multirow[b]{2}{*}{$\begin{array}{c}\text { (A) } \\
\mathrm{L}\end{array}$} & \multicolumn{3}{|c|}{ FEV1 } & \multicolumn{4}{|c|}{ FEV1 } & \\
\hline & & & & & (B) & $\begin{array}{l}5 \text { min } \\
\% \text { fall }\end{array}$ & $\begin{array}{l}5 \text { min } \\
\% \text { fall }\end{array}$ & & $\begin{array}{c}\text { (B) } \\
\mathrm{L}\end{array}$ & $\begin{array}{l}5 \text { min } \\
\% \text { fall } c\end{array}$ & $\begin{array}{l}15 \mathrm{n} \\
\% \mathrm{fa}\end{array}$ & $\begin{array}{c}\text { (A) } \\
\mathrm{L}\end{array}$ & $\begin{array}{c}\text { (B) } \\
\mathrm{L}\end{array}$ & $\begin{array}{l}5 \text { min } \\
\% \text { fall }\end{array}$ & $\begin{array}{l}15 \text { min } \\
\% \text { fall }\end{array}$ & \\
\hline 1 & M & 6 & 1.36 & 1.35 & 1.22 & 16.4 & 9.8 & 1.25 & 1.32 & $\underline{11.4}$ & 5.3 & 1.42 & 1.42 & 15.5 & 0 & $\mathrm{~T}$ \\
\hline 2 & M & 8 & 1.47 & 1.77 & 1.82 & 34.1 & 12.1 & 1.87 & 1.80 & 5.6 & -3.9 & 1.65 & 1.85 & 4.3 & 2.7 & T,DSCG \\
\hline 3 & M & 9 & 1.65 & 1.60 & 1.62 & $\overline{46.3}$ & 35.2 & 1.92 & 1.95 & 19.5 & 29.7 & 1.80 & 1.80 & $\underline{19.4}$ & 7.2 & $\mathrm{~T}, \mathrm{BDP}$ \\
\hline 4 & M & 10 & 2.24 & 1.70 & 1.87 & 13.4 & 5.3 & 1.60 & 1.72 & -2.9 & -4.7 & 1.92 & 1.95 & -1.0 & -5 & DSCG \\
\hline 5 & $\mathrm{~F}$ & 10 & 1.69 & 1.55 & 1.57 & 9.6 & 22.3 & 1.62 & 1.65 & 9.1 & 1.8 & 1.62 & 1.57 & 4.5 & -1.9 & $\mathrm{~T}, \mathrm{BDP}$ \\
\hline 6 & M & 10 & 2.57 & 1.45 & 1.27 & 29.1 & $\overline{39.4}$ & 1.77 & 1.72 & -2.9 & $\underline{0}$ & 1.70 & 1.67 & $\underline{6.0}$ & 4.2 & $\mathrm{~T}, \mathrm{DSCG}$ \\
\hline 7 & M & 11 & 1.74 & 1.40 & 1.45 & 17.2 & 10.3 & 1.07 & 1.27 & 3.9 & $-\overline{6} .3$ & 1.42 & 1.32 & $-1 \overline{1.4}$ & -9.8 & None \\
\hline 8 & $\mathrm{~F}$ & 12 & 2.24 & 1.47 & 1.40 & $\overline{52.1}$ & $\underline{60.7}$ & 1.57 & 1.80 & $\overline{8.3}$ & 13.9 & 1.40 & 1.42 & 10.6 & 4.9 & $\mathrm{~T}, \mathrm{DSCG}$ \\
\hline 9 & $\mathrm{~F}$ & 13 & 2.02 & 1.32 & 1.45 & 40.0 & 43.4 & 1.50 & 1.55 & $\underline{18.1}$ & 8.4 & 1.37 & 1.60 & 23.8 & 15.6 & DSCG \\
\hline 10 & $\mathrm{~F}$ & 13 & 2.24 & 1.90 & 2.07 & 46.9 & 9.7 & 2.27 & 2.05 & 6.3 & 1.5 & 1.95 & 2.22 & 7.7 & 3.2 & $\mathrm{~T}$ \\
\hline 11 & M & 14 & 2.70 & 2.07 & 2.12 & $\overline{19.8}$ & 18.9 & 1.92 & 1.92 & $\underline{11.5}$ & -1.6 & 1.82 & 1.65 & 0 & $\underline{13.9}$ & T, BDP \\
\hline 12 & $\mathrm{~F}$ & 14 & 2.60 & 2.25 & 2.25 & 14.7 & -0.9 & 2.45 & 2.27 & 13.2 & 11.0 & 2.02 & 2.10 & 4.8 & 4.8 & None \\
\hline 13 & $\mathrm{~F}$ & 14 & 2.53 & 2.20 & 2.25 & $\underline{\overline{32.4}}$ & 24.4 & 2.30 & 2.05 & $\underline{-1.0}$ & -8.3 & 2.15 & 2.35 & $\underline{12.8}$ & 6.4 & T, DSCG \\
\hline Mea & & & & 1.69 & 1.72 & 28 & & 1.78 & 1. & $7.7 *$ & $3.6^{*}$ & 1.71 & & $7.5 *$ & $3.6^{*}$ & \\
\hline SD & & & & 0.32 & 0.37 & 14.5 & 17.8 & 0.41 & 0.29 & 7.2 & 10.3 & 0.26 & 0.32 & 9.2 & 6.9 & \\
\hline
\end{tabular}

Predicted FEV1 according to the equation of Nishima [12]. (A): FEV1 before inhalation; (B): FEV1 before exercise after pretreatment. \% fall in FEV1 at 5 or 15 min: (FEV1 (B) - FEV1 measured at 5 or 15 min after exercise) / FEV1 (B) $\times 100$. Two-way ANOVA: $\mathrm{F}=26.90 ; \mathrm{p}=0.0001$ (at 5 min after exercise); $\mathrm{F}=14.74 ; \mathrm{p}=0.0001$ (at $15 \mathrm{~min}$ after exercise). Scheffe's multiple comparison test: *: $\mathrm{p}<0.05$ as compared to normal saline group. No statistical significant differences in percentage fall between isotonic and hypotonic DSCG were observed. Underscore indicates maximum percentage fall in FEV1 among 5 and 15 min postexercise. FEV1: forced expiratory volume in one second; Pred: predicted; DSCG: disodium cromoglycate; M: male; F: female; ANOVA: analysis of variance; T: oral theophylline; BDP: beclomethasone dipropionate.

Table 2. - Individual pulmonary function and percentage fall in FEV 1 after exercise with inhalation by ultrasonic nebulizer (Study 2)

Pred $\quad \frac{\text { Control (normal saline) }}{\text { FEV1 }} \frac{\text { Hypotonic DSCG }}{\text { FEV1 }} \frac{\text { Isotonic DSCG }}{\text { FEV1 }}$

\begin{tabular}{|c|c|c|c|c|c|c|c|c|c|c|c|c|c|c|c|c|}
\hline $\begin{array}{l}\text { Subject } \\
\text { No. }\end{array}$ & Sex & $\begin{array}{l}\text { Age } \\
\text { Yrs }\end{array}$ & $\begin{array}{c}\text { FEV } 1 \\
\text { L }\end{array}$ & $\begin{array}{c}\text { (A) } \\
\mathrm{L}\end{array}$ & $\begin{array}{l}\text { (B) } \\
\mathrm{L}\end{array}$ & $\begin{array}{l}5 \text { min } \\
\% \text { fall }\end{array}$ & $\begin{array}{l}5 \text { min } \\
\% \text { fall }\end{array}$ & (A) & (B) & $\begin{array}{l}5 \text { min } \\
\% \text { fall }\end{array}$ & $\begin{array}{l}15 \mathrm{~min} \\
6 \text { fall }\end{array}$ & $\begin{array}{c}\text { (A) } \\
\mathrm{L}\end{array}$ & $\begin{array}{l}\text { (B) } \\
\mathrm{L}\end{array}$ & $\begin{array}{l}5 \text { min } \\
\% \text { fall }\end{array}$ & $\begin{array}{l}15 \text { min } \\
\% \text { fall }\end{array}$ & $\begin{array}{c}\text { Daily } \\
\text { medication }\end{array}$ \\
\hline 1 & F & 9 & 1.44 & 1.55 & 1.47 & $\underline{13.6}$ & 0 & 1.57 & 1.55 & $\underline{5.2}$ & -3.2 & 1.45 & 1.52 & $\underline{11.2}$ & 6.6 & $\begin{array}{c}\mathrm{T}, \mathrm{DSCG} \\
\text { BDP }\end{array}$ \\
\hline 2 & M & 10 & 1.74 & 1.27 & 1.30 & 7.7 & 2.3 & 1.20 & 1.17 & $\underline{6.0}$ & -2.6 & 1.27 & 1.32 & -7.6 & $\underline{0}$ & $\mathrm{~T}, \mathrm{BDP}$ \\
\hline 3 & M & 10 & 1.53 & 0.85 & 1.07 & $5 \overline{3.3}$ & 65.4 & 0.82 & 0.87 & $2 \overline{3.0}$ & 25.3 & 1.20 & 1.02 & 9.8 & $-1 \overline{2} .7$ & T, DSCG \\
\hline 4 & M & 10 & 1.53 & 1.30 & 1.25 & $\underline{40.0}$ & 6.4 & 1.32 & 1.35 & $\underline{14.8}$ & $\overline{13.3}$ & 1.17 & 1.32 & $\underline{45.5}$ & 35.6 & $\mathrm{~T}$ \\
\hline 5 & M & 10 & 1.74 & 1.00 & 0.92 & $\overline{72.8}$ & ND & 1.12 & 1.05 & $\overline{52.4}$ & (31.4) & 1.15 & 0.95 & $\overline{24.2}$ & (10.5) & $\mathrm{T}$ \\
\hline 6 & M & 10 & 1.36 & 1.15 & 1.10 & $\overline{57.3}$ & $\underline{59.1}$ & 1.20 & 1.17 & $\underline{6.0}$ & 1.7 & 1.30 & 1.37 & 27.0 & 5.1 & $\mathrm{~T}, \mathrm{DSCG}$ \\
\hline 7 & $\mathrm{~F}$ & 10 & 1.77 & 1.27 & 1.10 & 25.5 & 9.1 & 1.30 & 1.32 & $\underline{26.5}$ & 1.5 & 1.25 & 1.27 & 17.3 & 9.4 & T, DSCG \\
\hline 8 & $\mathrm{~F}$ & 10 & 1.44 & 1.02 & 0.82 & $\overline{48.8}$ & $\underline{57.3}$ & 0.85 & 0.8 & $\overline{12.5}$ & 41.3 & 1.22 & 1.30 & $\overline{44.6}$ & 15.4 & $\mathrm{~T}$ \\
\hline 9 & $\mathrm{~F}$ & 13 & 2.35 & 2.47 & 2.40 & 26.3 & $\overline{25.0}$ & 2.27 & 2.27 & $\underline{3.1}$ & 2.2 & 2.30 & 2.22 & -1.4 & 9.0 & $\mathrm{~T}$ \\
\hline ean & & & & 1.32 & 1.27 & 38.4 & 28.1 & 9 & 1.28 & $16.6^{*}$ & $9.9 *$ & 1.37 & 1.37 & $19.0^{*}$ & 8.6 & \\
\hline SD & & & & 0.48 & 0.47 & 21.6 & 28.0 & 0.43 & 0.44 & 15.7 & 15.9 & 0.36 & 0.36 & 18.4 & 12.9 & \\
\hline
\end{tabular}

Predicted FEV1 according to the equation of Nishima [12]. Two-way ANOVA: $F=6.97 ; \mathrm{p}=0.007$ (at 5 min after exercise); $\mathrm{F}=2.85$; $\mathrm{p}=0.09$ (at $15 \mathrm{~min}$ after exercise). Scheffe's multiple comparison test: *: $\mathrm{p}<0.05$ as compared to normal saline group. No statistical significant differences in percentage fall between isotonic and hypotonic DSCG were observed. Underscore indicates maximum percentage fall in FEV1 among 5 and 15 min postexercise. Average percentage fall in FEV1 at 15 min after exercise was calculated from 8 subjects. ND: Subject No. 5 was unable to perform spirometry 15 min after exercise due to severe EIB. Percentage fall indicated by parenthesis was excluded from analysis. EIB: exercise-induced bronchospasm; ND: not determined. For further definitions see legend to table 1.

in random order, in a single-blind method, on separate days. Tests were performed at least $48 \mathrm{~h}$ apart, within a 2 week period. Each of the three challenges was administered at approximately the same time of day.

Isotonic DSCG solution was prepared by adding 0.15 $\mathrm{mL}$ of $10 \% \mathrm{NaCl}$ to $2 \mathrm{~mL}$ of commercially available hypotonic DSCG solution. Osmolarities of 10 samples of hypotonic or isotonic DSCG solution were measured by osmometer (OSMOSTAT, Model OM-6020; DaiichiKagaku Co. Ltd, Tokyo, Japan). The osmolarity ranged
40-45 mOsm $\cdot \mathrm{L}^{-1}$ for the hypotonic solution and 280$290 \mathrm{mOsm} \cdot \mathrm{L}^{-1}$ for the isotonic solution.

Study 1. Normal saline, hypotonic DSCG or isotonic DSCG solution $(2 \mathrm{~mL})$ was inhaled by jet nebulizer (Devilbiss model 646). The gas flow was $5 \mathrm{~L} \cdot \mathrm{min}^{-1}$ by compressed air for 5 min during tidal breathing with the use of a noseclip. The nebulizer output was $0.2 \mathrm{~mL} \cdot \mathrm{min}^{-1}$, and mass median particle diameter was $4.5 \mu \mathrm{m}$. 
Study 2. The same solutions as used in Study 1 were inhaled by ultrasonic nebulizer (Devilbiss model $100 \mathrm{HJ}$ ), which generated an aerosol with a mass median particle diameter of $3 \mu \mathrm{m}$. Because of the higher output of the ultrasonic nebulizer, $4 \mathrm{~mL}$ of each solution was prepared for nebulization. Average output of the ultrasonic nebulizer were $1.2 \mathrm{~mL} \cdot \mathrm{min}^{-1}$, and inhalations were performed for $2 \mathrm{~min}$. Each subject was instructed to inhale the solution through a Hans-Rudolf 2-way valve (Model \# 2600, Kansas City, USA) by tidal breathing with a noseclip.

Exercise challenge. Exercise challenges were performed on a cycle ergometer (Bosch Erg 551, Germany) for 6 min at $15 \mathrm{~min}$ after inhalation. The workload was set at 2.4 $\mathrm{W} \cdot \mathrm{kg}^{-1}$. During exercise, subjects wearing a face mask breathed compressed dry air (water content less than 1\%) through the Hans-Rudolf 2-way valve from a Douglas bag reservoir. Minute ventilation $\left(V^{\prime} \mathrm{E}\right)$ and oxygen consumption $\left(V^{\prime} \mathrm{O}_{2}\right)$ were measured continuously breath-bybreath (Sensor Medics, MMC 4400 TC), and heart rate was also monitored during exercise. Averaged $V^{\prime} \mathrm{E}$ and $V^{\prime} \mathrm{O}_{2}$ for the last $4 \mathrm{~min}$ and maximum heart rate during exercise were considered as indices to ascertain that a similar workload was given during challenges with different pretreatments. $V^{\prime} \mathrm{E}$ was corrected for individual predicted forced expiratory volume in one second (FEV1) and $V^{\prime} \mathrm{O}_{2}$ was, corrected for body weight. The FEV1 was measured before inhalation, before exercise, and 5 and 15 min after exercise using a spirometer (Model AS-500; Minato Medical Science Co. Ltd, Osaka, Japan). Because the maximum drop in FEV1 has been observed 5-10 min after exercise in the previous studies [13, 14], values of FEV1 5 and 15 min after exercise were used for evaluation of EIB and recovery from EIB. The percentage fall in FEV1 after exercise challenge was calculated as follows:

$\%$ fall in FEV1 at 5 or 15 min $=(\mathrm{FEV} 1$ before exercise - FEV1 at 5 or 15 min after exercise) / FEV1 before exercise $\times 100$

Maximum $\%$ fall in FEV1 $=(\mathrm{FEV} 1$ before exercise lowest FEV1 after exercise) / FEV1 before exercise $\times 100$

\section{Statistical analysis}

Results are expressed as mean \pm SD. Data were compared by analysis of variance (ANOVA) with two factors to test whether the percentage fall in FEV1 and the different treatments would significantly affect the measured variables. When a significant F-ratio was obtained, the difference between the means was isolated with the Scheffe's multiple comparison test. All tests were twotailed. A p-value of less than 0.05 was considered to indicate a statistically significant difference.

\section{Results}

Individual spirometric data $(\mathrm{FEV} 1)$ obtained before inhalation and exercise are presented in tables 1 and 2 . There were no significant differences in baseline FEV1 (i.e. before inhalation) among the different treatment groups in either study. Baseline FEV1 was not significantly changed after the inhalation of normal saline, hypotonic DSCG solution, or isotonic DSCG solution. There were no significant differences in FEV1 before exercise among the different treatment groups. Maximum heart rate, $V^{\prime} \mathrm{E}$, and $V^{\prime} \mathrm{O}_{2}$ measured during exercise are summarized in table 3 . There were no significant differences in these parameters during exercise between the different treatment groups in both studies.

The percentage fall in FEV1 at 5 and 15 min after exercise in each subject are shown in tables 1 and 2 . Mean values for percentage fall in FEV1 at 5 and 15 min after exercise with the inhalation of normal saline (control) were $28.6 \pm 14.5$ and $22.4 \pm 17.8 \%$ in Study 1 , and $38.4 \pm 21.6$ and $28.1 \pm 28.0 \%$ in Study 2, respectively. One of nine subjects (No. 5) in Study 2 showed a marked fall in FEV1 5 min after exercise with normal saline $(72.8 \%)$, and he was unable to perform spirometry at 15 min after exercise. In both studies, the administration of hypotonic or isotonic DSCG significantly reduced the EIB compared with normal saline at $5 \mathrm{~min}$ after exercise. No significant difference was observed between normal saline and isotonic DSCG 15 min after exercise in Study 2. There were no significant differences between the hypotonic and isotonic DSCG at any time (tables 1 and 2).

After the inhalation of hypotonic or isotonic DSCG by ultrasonic nebulizer (Study 2), four of the nine subjects (Nos. 3-6) showed considerable differences in protective effect against EIB. In two of the four subjects, the protective effect of hypotonic DSCG was less than that of isotonic DSCG and the reverse was true in the other two subjects. Hypotonic and isotonic DSCG administered by jet nebulizer (Study 1) provided similar protective effects in all subjects, the differences in maximum percentage fall between hypotonic and isotonic DSCG being within $15 \%$.

In the normal saline group, the maximum percentage

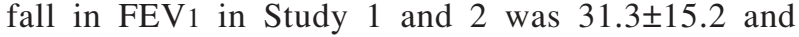

Table 3. - Heart rate, ventilation and oxygen uptake during exercise challenge

\begin{tabular}{|c|c|c|c|c|c|c|}
\hline \multirow[b]{2}{*}{ Group } & \multicolumn{3}{|c|}{ Study 1} & \multicolumn{3}{|c|}{ Study 2} \\
\hline & $\begin{array}{c}f \mathrm{C}, \max \\
\text { beats.min }\end{array}$ & $\begin{array}{l}V^{\prime} \mathrm{E} / \text { pred FEV1 } \\
\mathrm{L} \cdot \mathrm{min}^{-1} \cdot \mathrm{L}^{-1}\end{array}$ & $\begin{array}{c}V^{\prime} \mathrm{O}_{2} / \mathrm{kg} \\
\mathrm{L} \cdot \mathrm{min}^{-1} \cdot \mathrm{kg}^{-1}\end{array}$ & $\begin{array}{c}f \mathrm{C} \text {,max } \\
\text { beats } \cdot \min ^{-1}\end{array}$ & $\begin{array}{c}V^{\prime} \mathrm{E} / \text { pred FEV } 1 \\
\mathrm{~L} \cdot \mathrm{min}^{-1} \cdot \mathrm{L}^{-1}\end{array}$ & $\begin{array}{c}V^{\prime} \mathrm{O}_{2} / \mathrm{kg}^{-1} \\
\mathrm{~L} \cdot \mathrm{min}^{-1} \cdot \mathrm{kg}^{-1}\end{array}$ \\
\hline Control (saline) & $175 \pm 6.6$ & $18.9 \pm 2.5$ & $35.5 \pm 7.7$ & $182 \pm 8.5$ & $28.5 \pm 3.3$ & $44.8 \pm 5.5$ \\
\hline Hypotonic DSCG & $174 \pm 7.7$ & $19.2 \pm 2.9$ & $34.7 \pm 7.1$ & $181 \pm 7.2$ & $27.9 \pm 3.5$ & $44.2 \pm 5.1$ \\
\hline Isotonic DSCG & $172 \pm 6.9$ & $19.2 \pm 2.8$ & $35.1 \pm 6.1$ & $182 \pm 8.1$ & $28.8 \pm 3.5$ & $43.8 \pm 4.9$ \\
\hline
\end{tabular}

Values are presented as mean \pm SD. No significant differences were observed between groups. $V^{\prime} \mathrm{E}$ was corrected for predicted (Pred) $\mathrm{FEV} 1$ and $V^{\prime} \mathrm{O}_{2}$ was corrected for body weight. $f \mathrm{C}$,max: maximum cardiac frequency; $V^{\prime} \mathrm{E}$ : minute ventilation; FEV1: forced expiratory volume in one second; DSCG: disodium cromoglycate; $V^{\prime} \mathrm{O}_{2}$ : oxygen consumption. 
a)

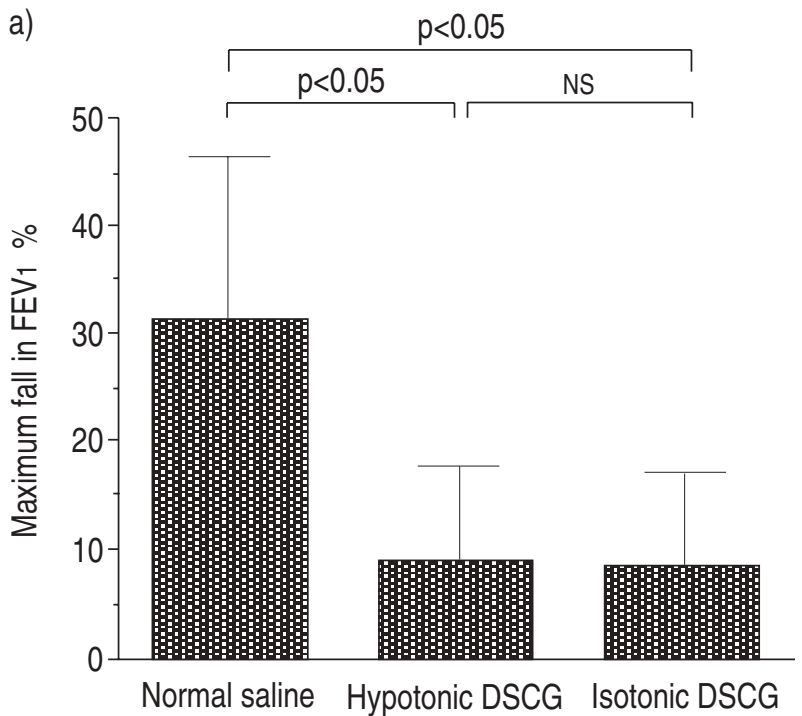

b)

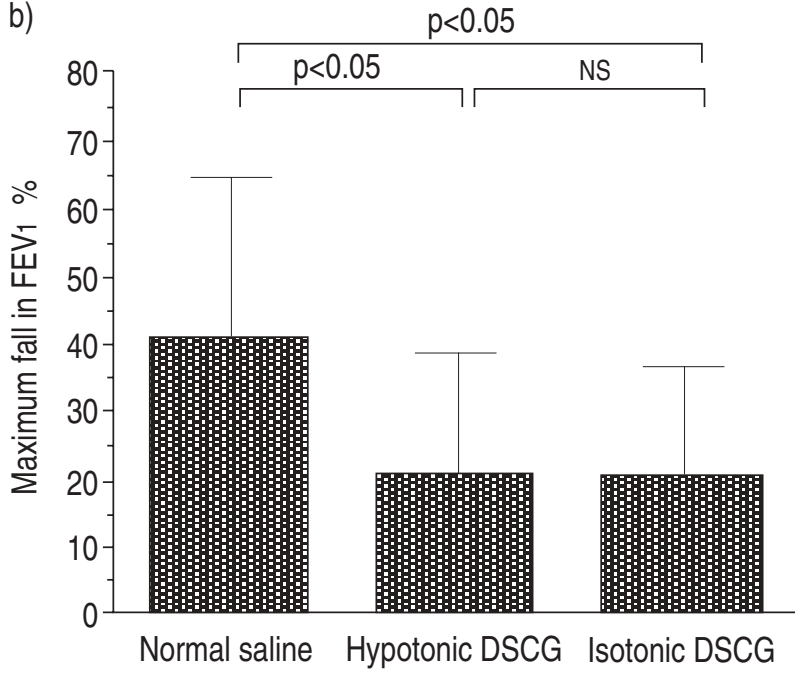

Fig. 1. - Maximum percentage fall in FEV1 after exercise challenge: a) in Study 1; and b) in Study 2. Data are expressed as meantSD. Twoway ANOVA: $\mathrm{F}=28.51 ; \mathrm{p}=0.0001$ (Study 1); $\mathrm{F}=6.93$; $\mathrm{p}=0.007$ (Study 2 ). Scheffe's multiple comparison test: $\mathrm{p}<0.05$ as compared to normal saline group. FEV1: forced expiratory volume in one second; DSCG: disodium cromoglycate; ANOVA: analysis of variance; NS: nonsignificant

$40.9 \pm 23.8 \%$, respectively (fig. 1 ). Both hypotonic and isotonic DSCG significantly reduced the maximum percentage fall in FEV1, $(9.1 \pm 8.8$ and $8.7 \pm 8.8 \%$ in Study 1 , $20.1 \pm 17.7$ and $21.0 \pm 15.9 \%$ in Study 2 , respectively). No significant differences between the two DSCG solutions were observed in the two studies.

\section{Discussion}

A previous study had shown that nebulized isotonic DSCG provided better protection against exercise- and methacholine-induced bronchoconstriction than hypotonic DSCG [8]. As the standard, commercially available DSCG solution is hypotonic, it is important to know whether an isotonic DSCG solution should be used in the clinical management of asthma.
The present study shows that a change in the osmolarity of the DSCG solution to isotonicity, did not afford additional protection against EIB. Because hypotonic DSCG is as effective as isotonic DSCG solution, it seems unlikely that the effect of DSCG on target cells, such as mast cells in the airways, could be reduced by a hypoosmolar stimulus during inhalation. An ultrasonic nebulizer has a greater influence on the osmolarity load in airways compared with a jet nebulizer because it produces dense aerosols and a higher output. However, our results obtained by jet nebulizer and ultrasonic nebulizer showed no difference between isotonic and hypotonic DSCG. It has also been reported that inhalation of a hypotonic stimulus, such as distilled water, produces bronchoconstriction in asthmatic subjects [15-17]. However, in the present study, inhalation of aerosolized hypotonic DSCG solution generated by ultrasonic nebulizer did not produce a significant fall in FEV1. Therefore, it is less likely that the effect of DSCG was influenced by the osmolarity of the solution. The reason that hypotonic DSCG did not cause bronchoconstriction may be that DSCG itself can protect against distilled water induced bronchoconstriction [9, $18]$.

Evaporative cooling, which can increase the osmolarity of droplets, has been demonstrated with a jet nebulizer [11]. The aerosol of normal saline generated by a jet nebulizer may lead to bronchoconstriction due to a hypertonic stimulus. However, we observed no significant difference in pulmonary function before versus after the inhalation of normal saline administered by a jet nebulizer. The effect of evaporative cooling on the osmolarity of aerosols seemed to be minimal in the present study although osmolarity of the solution in the nebulizer bowl was not measured during inhalation.

In Study 2, when an ultrasonic nebulizer was used, four of nine subjects showed a considerable difference in the protective effect obtained against EIB between isotonic and hypotonic DSCG. Differences in maximum percentage fall in FEV1 ranged 15.5-30.7\% in those subjects. Differences in maximum percentage fall in FEV1 between isotonic and hypotonic DSCG were small in Study 1 when a jet nebulizer was used for inhalation, ranging $1.3 \pm 13.7 \%$. Why the protective effects of inhaled isotonic and hypotonic DSCG with ultrasonic nebulizer were more variable compared with the effects of a jet nebulizer is unknown. It may be explained by differences in the subjects in Studies 1 and 2. More severe cases of EIB were thought to be enrolled in Study 2 because the magnitude of EIB was greater in that study. Also, the variability in protective effect against EIB in Study 2 could explain why isotonic DSCG did not produce significant protection against EIB compared with normal saline at $15 \mathrm{~min}$ after exercise. Further study is needed to compare the protective effects of hypotonic DSCG solution delivered by different nebulizers to the same subjects.

As lung function was measured only 5 and $15 \mathrm{~min}$ after exercise, results evaluated by maximum percentage fall in FEV1 may not be accurate because of subjects presenting further decrease of FEV1 after $15 \mathrm{~min}$. After the inhalation of hypotonic or isotonic DSCG, however, there were only a few subjects who developed a further decrease of lung function toward 15 min after exercise and there were no significant differences in percentage 
fall at 15 min between isotonic and hypotonic DSCG in either study. Therefore. it seems unlikely that isotonic DSCG is more effective against delayed bronchoconstriction after 15 min than hypotonic DSCG.

The discrepancy between the present results and those of WEINER et al. [8] could be explained by differences in the inhalation devices or in the methods of exercise challenge. The water content of the inspired air during exercise reportedly modifies the magnitude of EIB [18, 19]. Free running was the exercise in the study by WEINER et al. [8], whilst in the present study a cycle ergometer with dry air was used, which can provide more accurate and constant exercise. The workload and humidity of air inspired during exercise might have been variable in the study by WEINER et al. [8]. In their study, the average maximum percentage fall in FEV1 after inhalation of normal saline was about $25 \%$ : it was $31.3 \%$ in the present Study 1 and $40.9 \%$ in Study 2. Therefore, it is possible that the severity of EIB may have affected the results.

We conclude that hypotonic and isotonic solutions of disodium chromoglycate have similar efficacy in proviing protection against exercise-induced bronchospasm. Hypotonic disodium cromoglycate is thought to be clinically effective for preventing exercise-induced bronchospasm and treating children with bronchial asthma.

\section{References}

1. Davies SE. The effect of disodium cromoglycate on exercise-induced asthma. BMJ 1968; 3: 593-594.

2. Patel KR, Berkin KE, Kerr JW. Dose-response study of sodium cromoglycate in exercise-induced asthma. Thorax 1982; 37: 663-666.

3. Eggleston PA, Bierman CW, Pierson WE, Stamm SJ, Van Arsdel PP. A double-blind trial of the effect of cromolyn sodium on exercise-induced bronchospasm. $J$ Allergy Clin Immunol 1972; 50 (1): 57-63.

4. Corkey C, Mindorff C, Levison H, Newth C. Comparison of three different preparations of disodium cromoglycate in the prevention of exercise-induced bronchospasm. Am Rev Respir Dis 1982; 125: 623-626.

5. Carrasco E, Sepulveda R. Comparison of $1 \mathrm{mg}$ and 5 mg sodium cromoglycate metered-dose inhalers in the treatment of asthma: a 12 weeks double-blind, parallel group trial. Curr Med Res Opin 1989; 11: 341-352.
6. Robson RA, Taylar BJ, Taylor B. Sodium cromoglycate: spincaps or metered-dose aerosol. Br J Clin Pharmacol 1981; 11: 383-384.

7. Tullet WM, Tan KM, Wall RT, Patel KR. Dose-response effect of sodium cromoglycate pressurised aerosol in exercise-induced asthma. Thorax 1985; 40: 41-44.

8. Weiner P, Saaid M, Reshef A. Isotonic nebulized disodium cromoglycate provides better protection against methacholine- and exercise-induced bronchoconstriction. Am Rev Respir Dis 1988; 137: 1309-1311.

9. Anderson SD, Schoeffel RE, Finny M. Evaluation of ultrasonically nebulized solutions for provocation testing in patients with asthma. Thorax 1983; 38: 284-291.

10. Smith CM, Anderson SD. Inhalation provocation tests using nonisotonic aerosols. J Allergy Clin Immunol 1989; 84: 781-790.

11. Phipps PR, Pharm B, Gonda I. Droplets produced by medical nebulizers: some factors affecting their size and solute. Chest 1990; 97: 1327-1332.

12. Nishima S. Flow-volume curve in healthy and asthmatic children. Rinsho To Kenkyu 1977; 54: 185-190 (in Japanese).

13. Godfrey S, Silverman M, Anderson SD. Problems of interpreting exercise-induced asthma. J Allergy Clin Immunol 1973; 52: 199-209.

14. Morton AR, Lawrence SR, Fitch KD, Hahn AG. Duration of exercise in the provocation of exercise-induced asthma. Ann Allergy 1983; 51: 530-534.

15. Allegra L, Bianco S. Nonspecific bronchoreactivity obtained with an ultrasonic aerosol of distilled water. Eur J Respir Dis 1980; 61 (Suppl.): 41-49.

16. Sheppard D, Rizk NW, Boushey HA, Bethel RA. Mechanism of cough and bronchoconstriction induced by distilled water aerosol. Am Rev Respir Dis 1983; 127: 691-694.

17. Moscato G, Rampulla C, Dellabianca A, Zanotti E, Candura S. Effect of salbutamol and inhaled sodium cromoglycate on the airway and neutrophil chemotactic activity in "fog"-induced bronchospasm. J Allergy Clin Immunol 1988; 82: 382-388.

18. Argyros GJ, Philips YY, Rayburn DB, Rosenthal RR, Jaeger JJ. Water loss without heat flux in exercise-induced bronchospasm. Am Rev Respir Dis 1993; 147: 1419-1424.

19. Boulet LP, Turcotte H. Influence of water content of inspired air during and after exercise on induced bronchoconstriction. Eur Respir J 1991; 4: 979-984. 